\title{
A congested capacitated multi-level fuzzy facility location problem: An efficient drone delivery system
}

DOI:

10.1016/j.cor.2019.04.001

\section{Document Version}

Accepted author manuscript

Link to publication record in Manchester Research Explorer

\section{Citation for published version (APA):}

Shavarani, S. M., Mosallaeipour, S., Golabi, M., \& Izbirak, G. (2019). A congested capacitated multi-level fuzzy facility location problem: An efficient drone delivery system. Computers \& Operations Research, 108, 57-68. https://doi.org/10.1016/j.cor.2019.04.001

\section{Published in:}

Computers \& Operations Research

\section{Citing this paper}

Please note that where the full-text provided on Manchester Research Explorer is the Author Accepted Manuscript or Proof version this may differ from the final Published version. If citing, it is advised that you check and use the publisher's definitive version.

\section{General rights}

Copyright and moral rights for the publications made accessible in the Research Explorer are retained by the authors and/or other copyright owners and it is a condition of accessing publications that users recognise and abide by the legal requirements associated with these rights.

\section{Takedown policy}

If you believe that this document breaches copyright please refer to the University of Manchester's Takedown Procedures [http://man.ac.uk/04Y6Bo] or contact uml.scholarlycommunications@manchester.ac.uk providing relevant details, so we can investigate your claim.

\section{OPEN ACCESS}




\section{Accepted Manuscript}

A Congested Capacitated Multi-Level Fuzzy Facility Location Problem: An Efficient Drone Delivery System

Seyed Mahdi Shavarani, Sam Mosallaeipour, Mahmoud Golabi, Gokhan Izbirak

PII:

DOI:

Reference:

To appear in:

Received date:

Revised date:

Accepted date:
S0305-0548(19)30078-4

https://doi.org/10.1016/j.cor.2019.04.001

CAOR 4672

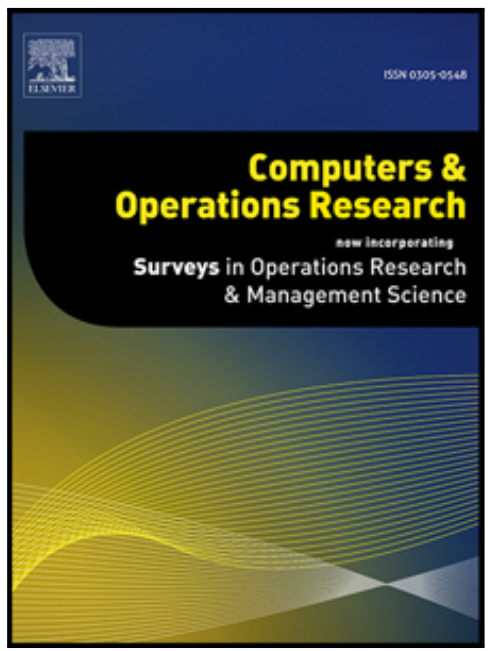

Please cite this article as: Seyed Mahdi Shavarani, Sam Mosallaeipour, Mahmoud Golabi, Gokhan Izbirak, A Congested Capacitated Multi-Level Fuzzy Facility Location Problem: An Efficient Drone Delivery System, Computers and Operations Research (2019), doi: https://doi.org/10.1016/j.cor.2019.04.001

This is a PDF file of an unedited manuscript that has been accepted for publication. As a service to our customers we are providing this early version of the manuscript. The manuscript will undergo copyediting, typesetting, and review of the resulting proof before it is published in its final form. Please note that during the production process errors may be discovered which could affect the content, and all legal disclaimers that apply to the journal pertain. 


\section{HIGHLIGHTS}

- Logistics and Economics of an aerial delivery system is investigated.

- Fuzzy variables are utilized to capture the uncertainties of the problem.

- A congested model is provided to account for the waiting time of the customers.

- Multi-level facility location model is used to model Different levels of the system.

- Case studies are provided to illustrate the efficiency of the proposed model. 


\section{A Congested Capacitated Multi-Level Fuzzy Facility Location Problem: An Efficient Drone Delivery System}

Seyed Mahdi Shavarani ${ }^{1}{ }^{*}$, Sam Mosallaeipour ${ }^{2}$, Mahmoud Golabi $^{3}$, Gokhan Izbirak $^{4}$

${ }^{1}$ Alliance Manchester Business School, University of Manchester, Manchester, UK

${ }^{2} \mathrm{Nhl}$ Stenden university of applied science, Technical Business School (Technische Bedrijfskunde),

Academy of Technology and Innovation, Leeuwarden, The Netherlands.

${ }^{3}$ Department of Industrial Engineering, Girne American University, Girne, Turkey

${ }^{4}$ Department of Industrial Engineering, Eastern Mediterranean University, Famagusta, Turkey

*Corresponding Author: Shavarani@ postgrad.manchester.ac.uk https://orcid.org/0000-0002-3316-1252

Tel: +447845013049 


\begin{abstract}
Online retailers invest an enormous amount of funds in delivering products to customers. In recent years, these delivery costs have increased as a result of changes in fuel costs, which has brought new challenges to retailers in terms of offering competitive prices. Many retailers have begun to utilize a drone-based aerial delivery system as an alternative solution to overcome the problems related to the high transportation costs and traffic jams in large cities. This study provides a mathematical model for minimizing the total costs of the aerial delivery system concerned with refuel stations, warehouses, drone procurement, and transportation. The waiting time of the customers is restricted based on the $\mathrm{M} / \mathrm{G} / \mathrm{K}$ queueing system. The fuel stations and warehouses are the main components of the network. The demand (occurring at the lowest level) is ultimately satisfied via launch stations (the network's highest level). Refuel stations support drones along their long routes between the launch stations and demand points. To account for the different levels of the facilities, a multi-level facility location approach is utilized. Moreover, the nondeterministic nature of the problem is tackled using fuzzy variables. The ultimate mathematical model is a congested fuzzy capacitated multi-level facility location problem that is solved by the possibilistic approach.
\end{abstract}

\title{
1. Introduction
}

In today's modern market, the management of supply chain and efficient delivery of goods and services to customers have become the most essential and challenging components of a successful business. This relatively new issue has resulted in fierce competition among the major players in the global market. Considering the currently tremendous pool of demand, companies strive to provide increasingly effective faster, cheaper, and more convenient delivery options. [1] opined that due to the prolonged time the customers have to spend at the mall for shopping, home delivery of numerous categories of goods and services is becoming the most mainstream delivery means in current society.

On the other hand, there are major obstacles to the successful delivery of goods and services to customers in highly populated metropolises. As reported by [2], the difficulties associated with transportation, particularly traffic jams in large cities (which lead to delays most of the time) and high fuel costs have made this method unsatisfactory and expensive. In the past few years, various researchers have proposed and adapted several effective solutions to the aforementioned setbacks using principles of supply chain management and logistics.

According to [3], one way of tackling these complications is utilizing drones for the delivery of products or services. This solution has attracted the interest and investment of many reputable companies, including Amazon, Google, and DHL. The core idea of the majority of studies on the utilization of aerial delivery systems is to develop an accurate model for optimizing the routing of the drones and for efficiently scheduling the operations. Interestingly, drone delivery applications are cultivated to cover a wider variety of applications, from pizza delivery in large cities to document delivery in the United Arab Emirates. Recently, [4] has revealed that even drone-taxis are being initiated in some cities.

Drones as a means for delivery purposes seem to be a viable and promising solution; however, application is hampered by the need to contemplate some important sets of parameters. Some of the most prominent variables in this regard are the number of launch and relaunch facilities, the capacity of the launching sites, the number of drones in each facility, and the endurance of the drones. It has been further substantiated by [5] that the proper deliberation and description of the 
mentioned variables depend largely on the ability to determine the best locations from where the services or goods are to be delivered to the customers.

The above-mentioned problem has been addressed by facility location problems (FLP) in the literature. The FLP deal with the problem of selecting a set of facilities from a set of candidate locations, satisfying demand as efficiently as possible under some given constraints. Generally, the aim is to minimize the total weighted distances between the providers and the customers. In the literature, the weights normally express the difficulty in terms of the degree of transportation, or simply the travel distance. A solution to this problem is expected to choose the facility locations such that maximum profit and customer satisfaction are acquired.

According to [6], deciding on the location of a facility is an imperative factor in the strategic planning of delivery networks. This issue has attracted attention towards proposing models for the determination of the most profitable locations for the facilities. A typical facility location problem usually includes a set of customers, as well as goods/service providers, and in which the distances and traveling times (or transportation costs) between facilities and clients is measured by a specific criterion. In these problems, the answer to the following three questions posed by [7] and [8] have fundamental significance: (i) how many facilities are required. (ii) which target customers are to be served by each facility, and (iii) which strategy delivers the minimum amount of cost? According to [9], FLP were first studied by Cooper, in 1963, trying to determine the location of several warehouses with respect to the demand points that had to be met through each warehouse. The implementation of this concept in network design was first discussed in [10]. The economic advantages of drone utilization for commercial purposes were addressed by [11]. They investigated various battery configurations to minimize the costs related to electricity and battery purchases. The delivery time, as well as the total number of facilities in a drone-truek delivery system, are minimized by [12]. Similarly, the application of drone delivery has been discussed in the context of rescue operations [13], relief distribution [14], delivery [15], and healthcare [16]. Recently, [17] tried to optimize the location of recharging stations for UAVs (Unmanned Aerial Vehicle) in order to meet the demand in large cities.

Congested facility location problems are another issue in location problems in which customers have to wait in a queue to receive the service. Different versions of congested location problems with immobile servers were reviewed by [18]. In the case of mobile servers, the service time accounts for the round-trip time between the facility and the location of demand, plus the probable on-scene and off-scene service time [19]. Therefore, considering a general distribution for service time is essential [20]. In this field, [19] studied a single-server single-facility location problem using M/G/1 queuing systems. Considering the same queuing framework, [21] expanded the previous study to locate $n$ facilities on a network. Applying M/G/k queuing systems, [20] proposed a model for the general kservers and n-facility location problem. Using discrete event simulations, they showed that the approximation method devised by [22] is appropriate for a congested location problem in an M/G/k environment. The queuing system discussed in this paper follows the M/G/k model.

\subsection{The impact of uncertain factors}

As described by [9], most of the current studies on FLP are marred with inadequacies resulting from considering customers' demands as deterministic, neglecting the variations in travel durations, and assuming linear functions for costs. Hence, without considering the uncertainties that are associated with the parameters, the output of the proposed models of the problem will be unrealistic and vague. This inadequacy has been addressed by several researchers incorporating the stochastic nature of the variables into the model [23]-[25]. 
Although stochastic models can be effective in a large range of cases, they are unable to represent the majority of the scenarios where the probability distributions of the uncertain parameters are entirely or partially unknown. In such cases, the best applicable approach for obtaining a better understanding of the problem, as well as the appropriate modeling approach is to consult the experts (more precisely, the person(s) who has enough knowledge about the topic) and collect the data from the professional point of view [26]. The empirical data acquired from experts is normally contaminated with some degree of uncertainty. Such a characteristic of the uncertain variables may be captured by employing the fuzzy variables during the modeling of the problem [27]. In fuzzy theory, when an uncertain variable, such as a customer's demand, is stated as "around 93", a fuzzy variable must be utilized to illustrate the concept of "around 93". In reality, "around 93" might be anything between 85 and 100. Thus, a corresponding hypothetical trapezoidal membership function can be defined to show the membership degree of the demand over a specified interval. For decades this method has been a common practice for dealing with uncertainties found in these problems [25], [28], [29]. Unfortunately, interpreting the membership functions and utilizing them for solving a problem is not an easy task [9]. Researchers have proposed several ways of providing an adequate solution to the problems that deal with the uncertain parameters [30]. One of the best methods for dealing with this category of problems is the "uncertainty theory" introduced by [31] and [32], which has attracted lots of attention recently [33]-[35]. Similarly, [36] utilized the concept of uncertainty theory to successfully solve an uncertain supplier-material selection problem. The concept is based on the expected value of the fuzzy variables and the degree to which an independent fuzzy variable will be greater than or equal to another independent fuzzy variable in a fuzzy possibilistic programming approach.

Generally, when dealing with uncertainty there is a need to construct models that are immune and insensitive to the uncertainty in the data. In 1973, Soyster proposed a linear optimization model to provide feasible solutions for all the data within the convex set of the decision space. Simply speaking, in this approach the solution space is reduced by considering the supreme values of these factors subject to the uncertainty, The feasibility of all the possible solutions obtained from this method had the price of losing potentially good solutions. Later on, other methods were proposed to overcome the over-conservatism of Soyster's method [37]-[39]. The drawback of these methods is in the non-linearity associated with them. Bertsimas and Sim (2004) proposed a robust optimization approach which permitted full control of the conservatism, even while still keeping the model linear [40]. However, this method is plagued with an increased number of variables and constraints. Other methods proposed for coping with the uncertain factors in the model are discussed in [41]-[44].

The possibilistic approach, as proposed by [42], first transforms the fuzzy trapezoidal numbers into equivalent intervals. In this approach, the feasibility level of the relations, a coefficient termed $\alpha$, is defined by the decision maker who controls the level of reliability and conservatism. The higher the value of $\alpha$, the more conservative the model. By considering $\alpha=1$, the model provided by the possibilistic approach would be the same as that of Soyster's method. Furthermore, the possibilistic approach does not add to the complexity of the problem. The method is extensively discussed in section 2.4 .

In this study, customer demands, the costs of opening a new facility, the costs of drone procurement and the distance capacity of the drones are considered as uncertain variables for which fuzzy variables are employed to reflect their uncertain characteristics. These characteristics create a suitable problem setting for utilizing the possibilistic approach; however, slight modifications might be required before this method can be utilized [36]. It should be noted that the possibilistic approach 
does not provide the crisp equivalent of the fuzzy relations in the case of nonlinearity or dependent fuzzy variables; hence, utilizing the concept of expected value in such relations solves this problem easily. This modification is incorporated into the original model for dealing with the complex formulation of the current Congested Capacitated Multi-Level Fuzzy Facility Location Problem. Some of the most significant advantages of the possibilistic programming approach that make it a suitable solution for this problem are the following: it is easy to implement, it may employ trapezoidal and triangular fuzzy variables, it enables the decision maker to obtain the optimal solution depending on the desirable feasibility degree, and, more importantly, it uses strong mathematical concepts such as expected interval and expected value of the fuzzy numbers. This method achieves the crisp equivalent of the mentioned fuzzy formulation, which is solvable using the regular approaches.

The remainder of this paper is organized as follows: in section 2, a brief description of the problem along with some essential preliminaries is laid out; in sections 3 , the fuzzy mathematical formulation of the problem is proposed; section 4 provides details on the application of the fuzzy possibilistic approach for transforming the proposed fuzzy model into its crisp equivalent; section 5 illustrates the performance and effectiveness of the proposed methodology through a case study; and the $6^{\text {th }}$ section of this paper presents the conclusion and directions for future research.

\section{Preliminaries and Problem Formulation}

\subsection{Definitions and Preliminaries}

Before proceeding any further, the following definitions must be considered:

1. Warehouses: Warehouses are the initial takeoff locations for the drones. They are considered as the main nest for the drones. Opening a launch center requires more infrastructure in comparison with the refuel stations.

2. Refuel stations: These centers are designed for extending the coverage of the drones by giving them the possibility to refuel/recharge on their way to demand points.

3. Capacitated facilities: The capacity of each facility is determined by the total number of assigned drones. The model seeks the best configuration to fully satisfy demand. It is supposed that the set of candidate locations is known, and therefore the problem is defined as discrete FLP.

The demand oecurrence on each node is assumed to follow a Poisson distribution. The distance between the launch point and the landing of a drone, no matter the warehouse or refuel station, is called a "trip". The lengths of trips cannot be greater than the endurance of the drones. Each mission of the drone could consist of as many trips as needed. A drone may visit one or more refuel stations on its route to satisfy demand. The distances between facilities are Euclidean, and the length of the total route from the warehouse to the demand point is calculated based on the Dijkstra algorithm. Each drone has a distance capacity during the planning period. The number of drones assigned to each facility is determined based on the total demand assigned to that facility and the travel distance required to cover this demand. Each drone is considered as a server. If drones are available, they are immediately dispatched to the demand point. If drones are busy, customers wait in a queue within an $\mathrm{M} / \mathrm{G} / \mathrm{k}$ framework. The number of open facilities is a decision variable. It is assumed that the average waiting time at each open facility should not exceed a predetermined threshold. The potential locations of facilities are predetermined and discrete, and can be used to establish launch or refuel stations. The 
establishment cost of refuel stations is supposed to be significantly lower than that of launch stations. Finally, a usage cost is incurred in each drone's mission.

\subsection{Problem Specification}

In this study, the optimization of a drone delivery system comprised of refuel stations and warehouses is considered. Since the warehouses also serve as the launch stations, the words "warehouse" and "launch station" are used equivalently in this article. To cover the whole area of the city, the refuel stations should be established in specific locations in the area. A drone may visit one or more refuel stations during its journey between the warehouses and customers. The frequency of refueling depends on drone endurance and the distance traversed. The endurance of a drone is defined as the maximum distance that can be flown by a drone without being refueled. The length of the shortest path from a demand to the nearest warehouse is equal to the Euclidean distance if no refueling is required; otherwise, this length is acquired using the shortest path algorithm. Since the location of refuel stations is a decision variable, the length of the shortest path is variable as well. Similarly, the total number of facilities to be established is a decision variable for both refuel stations and warehouses. Moreover, the price of refuel stations is significantly lower than warehouses, and a customer is served by the closest warehouse. Furthermore, all demand should be satisfied.

Four major costs could be addressed in these problems: establishment costs of the launch stations, establishment costs of refuel stations, and procurement and uságe costs of the drones. Usage costs are normally addressed as maintenance, fuel and depreciation costs, and they have a direct relationship with the distance traveled, thus they are all calculated per distance unit. It is imperative to integrate such costs in the objective function as a coefficient multiplied by the aggregate travel distance. The speed of drones is fixed and identical. Therefore, the minimization of the usage costs would be equivalent to minimizing the traveling time.

In each working shift, a drone can travel a maximum distance according to its specifications, such as its speed and endurance. This distance is considered as the distance capacity of a drone. Consequently, the distance capacity of a facility is defined as the total distance that can be covered by a facility, which is equal to the sum of the distance capacities of all the drones assigned to that facility. Thus, the number of drones assigned to each facility is a function of the demands assigned to it and the total travel distance required for satisfying them.

\subsection{Fuzzy Mathematical Formulation}

In this section, the fuzzy mathematical formulation is presented based on the characteristics and assumptions of the problem mentioned in the previous sections. In this model, the uncertainty of the variables is reflected through fuzzy variables; a tilde over the variables indicates their fuzziness. The following notations are used to introduce the mathematical formulation of the problem.

Sets:

$V$ : The set of nodes $\left(v, v^{\prime} \in V\right)$

$J$ : The set of candidate locations $\left(j, j^{\prime} \in J, J \subseteq V\right)$

Scalars:

$M$ : A large positive number

Parameters:

$\widetilde{c l}$ : The cost of opening a new launch station at candidate location $\mathrm{j}$

$\widetilde{c r}$ : The cost of opening a new refuel station at candidate location $\mathrm{j}$ 
$\widetilde{c_{d}}$ : The price of each drone

$c_{g}$ : The usage cost of drone vehicles per distance unit

$d_{j j}$ : The Euclidean distance between facility $j$ and facility $j^{\prime}$

$d_{j v}$ : The Euclidean distance between facility $j$ and node $v$

$\widetilde{\lambda_{v}}$ : The demand located on node $v$

$\widetilde{h_{v}}$ : The fraction of total demands originated from node $v$

$\tilde{\vartheta}:$ The speed of each drone

$\tilde{\rho}$ : The distance capacity of each drone during the planning period

$E$ : The endurance of each drone

$\tau_{j}$ : The maximum allowed waiting time at facility $j$

$M_{t}$ : The maximum allowed length of the route from the demand point to its assigned launch station

Variables:

$L_{j}=1$ if a launch station is established at location $j ; 0$ otherwise

$R_{j}=1$ if a refuel station is established at location $j ; 0$ otherwise

$y_{j}=1$ if a facility is established at location $j ; 0$ otherwise

$x_{j v}=1$ if node $v$ is assigned to facility $j ; 0$ otherwise

$w_{j}=$ The shortest path weight of node $j$

$t_{j v}$ : The length of the shortest path from facility $j$ to demand node $v$

$n_{j}$ : The total number of required drones in facility $j$

$n_{d}$ : The total number of required drones

$n_{g}:$ The aggregate utilization of drones

$\widetilde{\gamma_{j}}$ : The request for service at facility $j$

$\bar{S}_{j}$ : The first moment of service time at facility $j$

$\overline{S_{j}^{2}}$ : The second moment of service time at facility $j$

$\overline{T_{j v}}$ :The first moment of service time for demand node $v$ at facility $j$

$\overline{T_{j v}^{2}}$ : The second moment of service time for demand node $v$ at facility $j$

$\omega_{j}$ : The expected waiting time at facility $j$

Since demand generation is according to a Poisson distribution, the request for service at each open facility $j$ is a Poisson process with the following intensity: 
$\widetilde{\gamma_{J}}=\sum_{v \in V} \widetilde{\lambda_{v}} x_{j v}$

The fraction of total demands originating from demand node $v$ is calculated according to Eq. 2 .

$\widetilde{h_{v}}=\widetilde{\lambda_{v}} / \sum_{t \in V} \tilde{\lambda_{t}}$

For $\mathrm{M} / \mathrm{G} / \mathrm{k}$ queuing systems, the expected waiting time at each facility $\mathrm{j}$ is calculated as [20]:

$\omega_{j}=\frac{\widetilde{\gamma}_{j} \widetilde{n}_{j}{\widetilde{S_{j}}}^{2}{\widetilde{S_{j}}}^{k_{j}-1}}{2\left(n_{j}-1\right) !\left[n_{j}-\gamma_{j}{\overline{S_{j}}}_{j}\right] \sum_{i=0}^{k_{j}-1}\left(\left(n_{j}-i\right)\left(\widetilde{\gamma_{j}}{\widetilde{S_{j}}}^{i} / / !\right)\right.} \quad$ if $\widetilde{\gamma_{j}} \widetilde{\bar{S}_{j}}<n_{j}$

The first and second moments of service time at each facility $\mathrm{j}$ are calculated as [45]:

$\widetilde{S_{j}}=\sum_{v \in V} h_{v} \overline{T_{j v}} x_{j v}$

${\widetilde{S_{j}}}^{2}=\sum_{v \in V} h_{v} \overline{T_{j v}^{2}} x_{j v}$

The first and second moments of service time for demand node $v$ at facility $\mathrm{j}$ are calculated by Eq. 6 and Eq. 7 respectively [46].

$\widetilde{T_{j v}}=\frac{2 d_{j v}}{\tilde{\vartheta}}+\overline{z_{v}}$

$\widetilde{T_{j v}^{2}}=\left(\frac{2 d_{j v}^{2}}{\tilde{\vartheta}}\right)+2\left(\frac{2 d_{j v}}{\tilde{\vartheta}}\right)+{\overline{z_{v}}}^{2}$

$\overline{\mathrm{z}_{\mathrm{V}}}$ is the expected on-scene and off-scene service time at demand node $\mathrm{v}$, which, according to the essence of this study, could be neglected.

Using the described assumptions and definitions, the problem can be modeled as the following fuzzy formulation:

$\operatorname{Min} \sum_{j} \widetilde{c_{j}^{l}} L_{j}+\sum_{j} \widetilde{c_{j}^{k}} R_{j}+n_{d} \widetilde{c_{d}}+\widetilde{n_{g}} c_{g}$

Subject to:

$L_{j}+R_{j}=y_{j}$

$\forall j \in J$

$\sum_{j} x_{j v}=1$

$\forall v \in V$

$x_{j v} \leq y_{j}$

$\forall j \in J, v \in V$

$t_{j v}=\left(w_{v}-w_{j}\right)$

$\forall j \in J, v \in V$

$\left(w_{j}-w_{j^{\prime}}\right) y_{j} y_{j^{\prime}} \leq d_{j j^{\prime}}$

$\forall j,\left.j^{\prime} \in J\right|_{d_{j j} \leq E}$

$\left(w_{v}-w_{j}\right) y_{j} \leq d_{j v}$

$\forall j \in J,\left.v \in V\right|_{d_{j v} \leq E}$ 
$\sum_{j^{\prime} \in J} t_{j \prime v} x_{j \prime v} \leq t_{j v}+M\left(1-y_{j}\right)$

$n_{j} \geq \sum_{(v)} \widetilde{\lambda_{v}} t_{j v} x_{j v} / \tilde{\rho}$

$n_{g}=\sum_{j} \sum_{(v)} \widetilde{\lambda_{v}} t_{j v} x_{j v}$

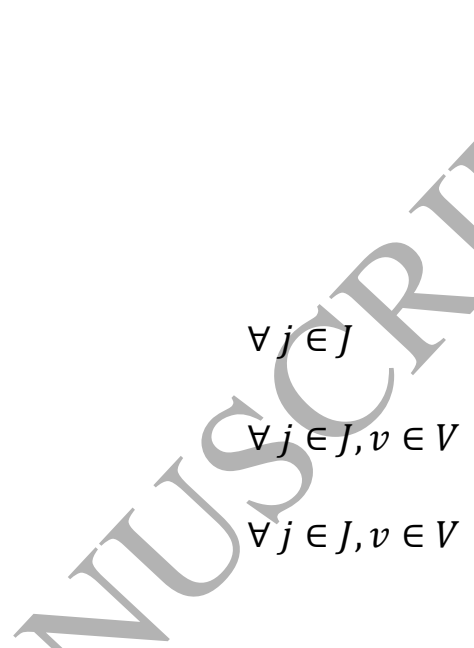

$n_{d}=\sum_{j} n_{j}$

$\omega_{j} \leq \tau_{j}$

$y_{j}, x_{j v}, L_{j}, R_{j} \in\{0,1\}$

$\forall j \in J, v \in V$

$w_{j}, t_{j v}, n_{j}, n_{g}, n_{d} \geq 0$

$\forall j \in J, v \in V$

The objective function of model (8) minimizes the total costs of the system. Constraint (9) refrains from establishing both the launch and refuel stations at a single candidate location. Constraint (10) ensures that each node is assigned to one station. Constraint (11) assures that demand is only assigned to opened facilities. Constraints (12) - (15) define the length of the shortest path between launch stations and demand points. The assignment of demands to the facility with the shortest path is guaranteed by constraint (16). Constraint (17) determines the minimum number of required drones for each facility. Drone utilization is reflected in constraint (18). The total number of drones is specified in equation (19). Constraint (20) guarantees that the waiting time does not exceed a predefined threshold. Binary and positive variables are defined in constraints (21) and (22) respectively.

The possibilistic programming approach is employed for the defuzzification of the proposed fuzzy model. In this approach, each parameter with epistemic uncertainty has a possibility distribution, which means the occurrence of each data point has a possibility degree that is determined by the knowledge of the experts. In the next section, the procedure of transforming the fuzzy model to its crisp equivalent using the possibilistic programming approach is discussed.

\subsection{The crisp equivalent of the fuzzy model using fuzzy possibilistic uncertainty theory}

Since this formulation utilizes fuzzy variables, it must be converted to its crisp equivalent before solving the problem. In this step, the concepts and definitions of the possibilistic method are described before it is employed to transform the fuzzy formulation:

Definition 1. Let $\tilde{\ell}=\left(\ell^{1}, \ell^{2}, \ell^{3}, \ell^{4}\right)$ be a trapezoidal fuzzy number with the following membership function: 


$$
\mu_{\tilde{\ell}}(x)=\left\{\begin{array}{cc}
\frac{x-\ell^{1}}{\ell^{2}-\ell^{1}} & \ell^{1} \leq x \leq \ell^{2} \\
1 & \ell^{2} \leq x \leq \ell^{3} \\
\frac{\ell^{4}-x}{\ell^{4}-\ell^{3}} & \ell^{3} \leq x \leq \ell^{4} \\
0 & \text { Otherwise }
\end{array}\right.
$$

The expected interval and expected value (EI \& EV respectively) of the trapezoidal fuzzy number $\tilde{\ell}=\left(\ell^{1}, \ell^{2}, \ell^{3}, \ell^{4}\right)$ are defined as follows [41]:

$$
\begin{aligned}
& E I(\tilde{\ell})=\left[E_{1}^{\ell}, E_{2}^{\ell}\right]=\left[\frac{\ell^{1}+\ell^{2}}{2}, \frac{\ell^{3}+\ell^{4}}{2}\right] \\
& E V(\tilde{\ell})=\frac{E_{1}^{\ell}+E_{2}^{\ell}}{2}=\frac{\ell^{1}+\ell^{2}+\ell^{3}+\ell^{4}}{4}
\end{aligned}
$$

Definition 2. According to [42], for any pair of fuzzy numbers $\ell$ and $\Upsilon$, the degree to which $\ell$ is bigger than $\Upsilon$ is defined as:

$\mu_{M}(\tilde{\ell}, \widetilde{\Upsilon})=\left\{\begin{array}{cc}0 & E_{2}^{\ell}-E_{1}^{\Upsilon}<0 \\ \frac{E_{2}^{\ell}-E_{1}^{\Upsilon}}{E_{2}^{\ell}-E_{1}^{\Upsilon}-\left(E_{1}^{\ell}-E_{2}^{\Upsilon}\right)} & 0 \in\left[E_{1}^{\ell}-E_{2}^{\Upsilon}, E_{2}^{\ell}-E_{1}^{\Upsilon}\right] \\ 1 & E_{1}^{\ell}-E_{2}^{\Upsilon}>0\end{array}\right.$

For the cases $\mu_{M}(\tilde{\ell}, \widetilde{\Upsilon}) \geq \alpha$, it is said that $\tilde{\ell}$ is bigger than or equal to $\widetilde{Y}$ at least in degree of $\alpha$. This relation is represented by $\tilde{\ell} \geq_{\alpha} \widetilde{Y}$.

Definition 3. For a pair of fuzzy numbers like $\ell$ and $\Upsilon$, the numbers are equal in degree of $\alpha$ (the feasibility level which is set by the decision maker) if the following relationship holds [47]:

$$
\frac{\alpha}{2} \leq \mu_{M}(\tilde{\ell}, \widetilde{\Upsilon}) \leq 1-\frac{\alpha}{2}
$$

Definition 4 If $\ell$ is defined as a linear combination of $\widetilde{Y^{1}}$ and $\widetilde{Y^{2}}$, then mathematically it is true that $\mathrm{EV}(\ell)=\mathrm{EV}$ (linear combination of $\widetilde{\Upsilon^{1}}$ and $\widetilde{\Upsilon^{2}}$ ).

In order to illustrate how the possibilistic method converts a fuzzy model to its crisp equivalent, consider the following general mathematical formulation:

$\min \widetilde{c^{T}} x$

Subject to

$$
\begin{array}{ll}
\widetilde{a_{l}} x \geq \widetilde{b_{l}} & i=1,2, \ldots, l \\
\widetilde{a_{\imath}} x=\widetilde{b_{l}} & i=l+1, \ldots, m \\
\ell=p_{1} \sum \widetilde{\Upsilon^{1}} \widetilde{\Upsilon^{2}} &
\end{array}
$$


$x \geq 0$

According to [41], vector $x \in \mathbb{R}^{n}$ will be feasible with $\alpha$ degree if $\min \left\{\mu_{M}\left(a_{i}^{\tilde{i}} x, b_{i}^{\sim}\right)=\alpha, i=\right.$ $1, \ldots, m\}$. Hence, $\alpha$ is considered as the degree of feasibility for the model which is decided by the decision maker (DM). A higher value of $\alpha$ corresponds to a smaller feasible solution space, and consequently the optimal solution becomes more conservative but less interesting.

Conferring from (26) and (27), the relation $a_{i}^{\tilde{x}} x \geq b_{i}^{\tilde{i}}$ and $a_{i}^{\tilde{x}} x=b_{i}^{\tilde{i}}$ can be expressed as the following:

$$
\begin{array}{cc}
\frac{E_{2}^{a_{i} x}-E_{1}^{b_{i}}}{E_{2}^{a_{i} x}-E_{1}^{b_{i}}-\left(E_{1}^{a_{i} x}-E_{2}^{b_{i}}\right)} \geq \alpha & i=1,2, \ldots, l \\
\frac{\alpha}{2} \leq \frac{E_{2}^{a_{i} x}-E_{1}^{b_{i}}}{E_{2}^{a_{i} x}-E_{1}^{b_{i}}-\left(E_{1}^{a_{i} x}-E_{2}^{b_{i}}\right)} \leq 1-\frac{\alpha}{2} & i=l+1, \ldots, m
\end{array}
$$

Substituting the equivalent equations into the original model implies the following key relations:

$\min \left[E V\left(c^{\sim T}\right)\right]$

subject to:

$$
\begin{aligned}
& \left((1-\alpha) E_{2}^{a_{i}}+\alpha E_{1}^{a_{i}}\right) x \geq \alpha E_{2}^{b_{i}}+(1-\alpha) E_{1}^{b_{i}} \quad i=1,2, \ldots, l \\
& \left(\left(1-\frac{\alpha}{2}\right) E_{2}^{a_{i}}+\frac{\alpha}{2} E_{1}^{a_{i}}\right) x \geq \frac{\alpha}{2} E_{2}^{b_{i}}+\left(1-\frac{\alpha}{2}\right) E_{1}^{b_{i}} y \\
& \left(\frac{\alpha}{2} E_{2}^{a_{i}}+\left(1-\frac{\alpha}{2}\right) E_{1}^{a_{i}}\right) x \leq\left(1-\frac{\alpha}{2}\right) \alpha E_{2}^{b_{i}}+\left(\frac{\alpha}{2}\right) E_{1}^{b_{i}} \quad i=l+1, \ldots, m \\
& \mathrm{EV}(\ell)=\mathrm{EV}\left(p_{1} \Sigma \widetilde{\Upsilon^{1}} \widetilde{\Upsilon^{2}}\right) \\
& x \geq 0
\end{aligned}
$$

Based on the above-mentioned relations, the crisp equivalent of the fuzzy objective function and constraints (17) $f(18)$ given above can be rewritten as the following:

$\operatorname{Min} \sum_{j}\left(\frac{c_{j}^{l 1}+c_{j}^{l 2}+c_{j}^{l 3}+c_{j}^{l 4}}{4} L_{j}+\frac{c_{j}^{r 1}+c_{j}^{r 2}+c_{j}^{r 3}+c_{j}^{r 4}}{4} R_{j}\right)+\frac{c_{d}^{1}+c_{d}^{2}+c_{d}^{3}+c_{d}^{4}}{4} n_{d}+\frac{n_{g}^{1}+n_{g}^{2}+n_{g}^{3}+n_{g}^{4}}{4} c_{g}$

subject to constraints (9)-(16) and (19)-(22) and:

$$
\begin{aligned}
& n_{j} \geq \sum_{(v)}\left(\alpha\left(\frac{\lambda_{v v \prime}^{3}+\lambda_{v v \prime}^{4}}{2}\right)+(1-\alpha)\left(\frac{\lambda_{v v \prime}^{1}+\lambda_{v v \prime}^{2}}{2}\right)\right) t_{j v} x_{j v} /\left(\alpha\left(\frac{\rho^{3}+\rho^{4}}{2}\right)+(1-\alpha)\left(\frac{\rho^{1}+\rho^{2}}{2}\right)\right) \quad \forall j \in J \\
& n_{g} \geq \sum_{j} \sum_{(v)}\left(\alpha\left(\frac{\lambda_{v v \prime}^{3}+\lambda_{v v \prime}^{4}}{2}\right)+(1-\alpha)\left(\frac{\lambda_{v v^{\prime}}^{1}+\lambda_{v v \prime}^{2}}{2}\right)\right) t_{j v} x_{j v}
\end{aligned}
$$


$n_{g} \leq \sum_{j} \sum_{(v)}\left(\alpha\left(\frac{\lambda_{v v^{\prime}}^{1}+\lambda_{v v \prime}^{2}}{2}\right)+(1-\alpha)\left(\frac{\lambda_{v y^{\prime}}^{3}+\lambda_{v v \prime}^{4}}{2}\right)\right) t_{j v} x_{j v}$

Where:

$\gamma_{j}=\sum_{v \in V}\left(\frac{\lambda_{v}^{1}+\lambda_{v}^{2}+\lambda_{v}^{3}+\lambda_{v}^{4}}{4}\right) x_{j v}$

$h_{v}=\left(\lambda_{v}^{1}+\lambda_{v}^{2}+\lambda_{v}^{3}+\lambda_{v}^{4}\right) / \Sigma_{t \in V}\left(\lambda_{t}^{1}+\lambda_{t}^{2}+\lambda_{t}^{3}+\lambda_{t}^{4}\right)$

$\overline{T_{j v}}=\frac{2 d_{j v}}{\left(\frac{v^{1}+\vartheta^{2}+v^{3}+v^{4}}{4}\right)}+\overline{z_{v}}$

$\overline{T_{j v}^{2}}=\frac{2 d_{j v}^{2}}{\left(\frac{\vartheta^{1}+\vartheta^{2}+\vartheta^{3}+\vartheta^{4}}{4}\right)}+2 \frac{2 d_{j v}}{\left(\frac{\vartheta^{1}+\vartheta^{2}+\vartheta^{3}+\vartheta^{4}}{4}\right)}+{\overline{z_{v}}}^{2}$

$\omega_{j}=\frac{\gamma_{j}^{n_{j}} \overline{S_{j}^{2}}\left(\overline{S_{j}}\right)^{n_{j}-1}}{2\left(n_{j}-1\right) !\left[n_{j}-\gamma_{j} \bar{S}_{j}\right] \sum_{i=0}^{n_{j}-1}\left(\left(n_{j}-i\right)\left(\gamma_{j} \bar{S}_{j}\right)^{i} / i !\right)}$

if $\gamma_{j} \overline{S_{j}}<n_{j}$

\section{Solution Method}

Due to the extreme nonlinearity of the proposed mixed integer nonlinear mathematical model, the exact methods were unable to solve even the small instances of the problem. To overcome this issue, a genetic algorithm is developed. Inspired by the eyolution of species found in nature through generations, John Holland devised the Genetic Algorithm (GA) in 1975 [48]. Since then many researchers have used the GA in their studies (see [49], [50]). The steps involved in the application of the GA are as follows:

Step 1 (Initialization): the parameters of the GA are initialized. These parameters are population size (Npop), the maximum number of iterations (MaxIt), crossover probability (Pc), mutation probability $(\mathrm{Pm})$, greedy search probability (GSp), and greedy search intensity (GSi).

Step 2 (Initial population): The GA initiates with a set of randomly generated solutions, called the initial population. As illustrated in Fig. 1(a), each solution is represented by a chromosome in which the $n^{\text {th }}$ gene indicates the status of the location for the $n^{\text {th }}$ candidate. The status of these locations can be of three forms, which are closed (C), warehouse (W) and recharge Station (R).

Step 3 (Fitness evaluation): After determining the location of the facilities, the assignment of demands is performed by the closest neighborhood assignment method. The distance between each node and any open facility is calculated using the Dijkstra algorithm. In the calculation of the shortest path, the distances between recharge stations and other facilities that are within the bounds of the expected value of their endurance are deemed as existing edges. If a node exhibits a characteristic of having its closest facility further than the endurance of the drones, then a penalty is imposed to prohibit the occurrence of such solutions in the next generation. The number of drones required for each facility is calculated based on the total demand assigned to that facility, the total travel distance to satisfy assigned demands, and the number of drones required to observe the constraint imposed by the maximum waiting time. The total cost of the system, which is considered to be the fitness value, is obtained by multiplying each of the elements of the system by the expected value of their cost. Each solution is then ranked based on its fitness function. 
Step 4 (Parent selection): In this step, a predetermined number of solutions are selected as parents to generate offspring/children. The parents are selected by the roulette wheel selection method, which gives higher priority to individuals with higher rank.

Step 4 (Crossover operator): Pairs of selected parents undergo a crossover operation to produce two new children (offspring). According to Fig. 1.b), a crossover point, which decomposes each parent into two different parts, is generated randomly across the length of the selected parents. The second parts of the chromosomes are then interchanged generating two new solutions. The number of offspring generated by the crossover operation is controlled by Pc. The increased population is then sorted based on their rank, and the best individuals are selected as the next generation.

Step 5 (Mutation operator): According to the mutation probability, (Pm*Npop) number of parents are selected to undergo the mutation operator. There are four different types of mutation that can be selected randomly and performed on the selected solution (parent). The mutate operator selects several genes randomly and alters their values. The reverse operator selects two points along the chromosome and reverses the order of the genes between these two points. The swap operator selects two genes randomly and changes their position and, finally, the insertion operator selects one gene randomly and inserts it in a new position (Fig. 1.c).

Step 6 (Greedy search): During the implementation of the GA, it was observed that some of the opened facilities do not contribute to the fitness value. Therefore, to improve the performance of the GA, a greedy algorithm is incorporated to the system. The greedy algorithm randomly selects a predetermined number of solutions, which is controlled by the GSp, and downgrades the level of the predetermined number of genes (GSi) within the chromosome. Downgrading a gene includes changing the launch stations to refuel ones and closing the gene otherwise. If the solution is improved in terms of its fitness function, the original solution is replaced with the superior one. The superiority of results obtained by the developed Hybrid GA compared with that of the GA is analyzed using a one-way ANOVA method (Appendix 1).

Step 7 (Updating the initial population): After adding the generated offspring to the initial population, the new population is sorted based on the rank of individuals. Then the size of the population is kept at its initial value by keeping the best solutions and discarding the rest.

Step 8 (Stopping Criteria): The algorithm stops after the predetermined number of iterations (MaxIt) is reached. Algorithm 1 shows the pseudo code of the proposed Hybrid GA and greedy search.

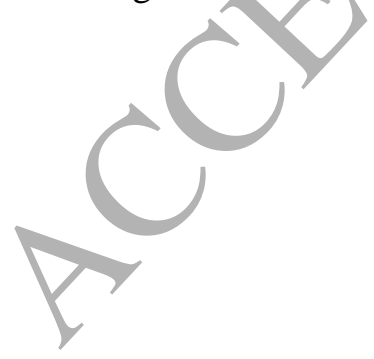




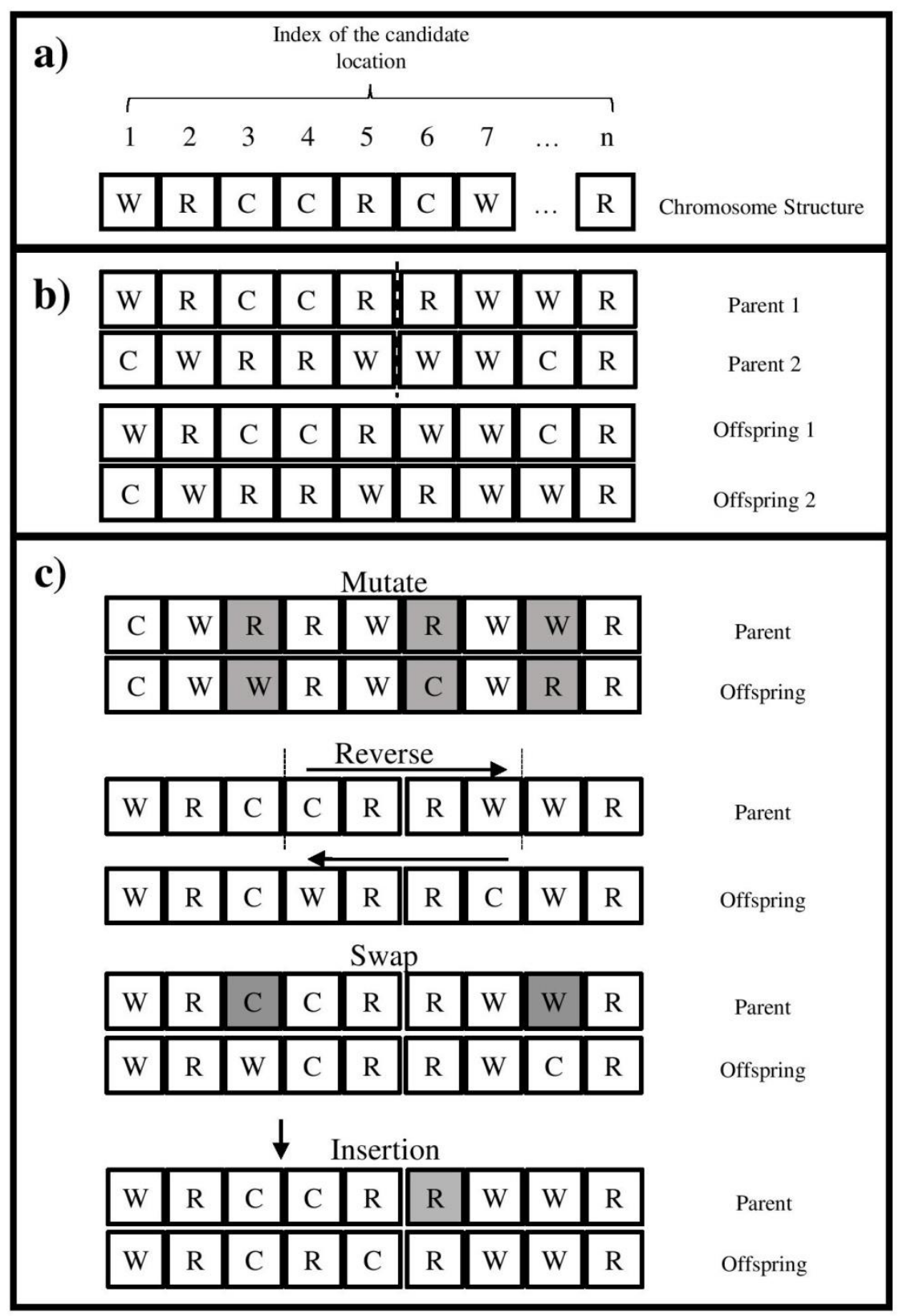

Fig. 1.a) The solution representation, b) Crossover operation, c) Mutation operation 


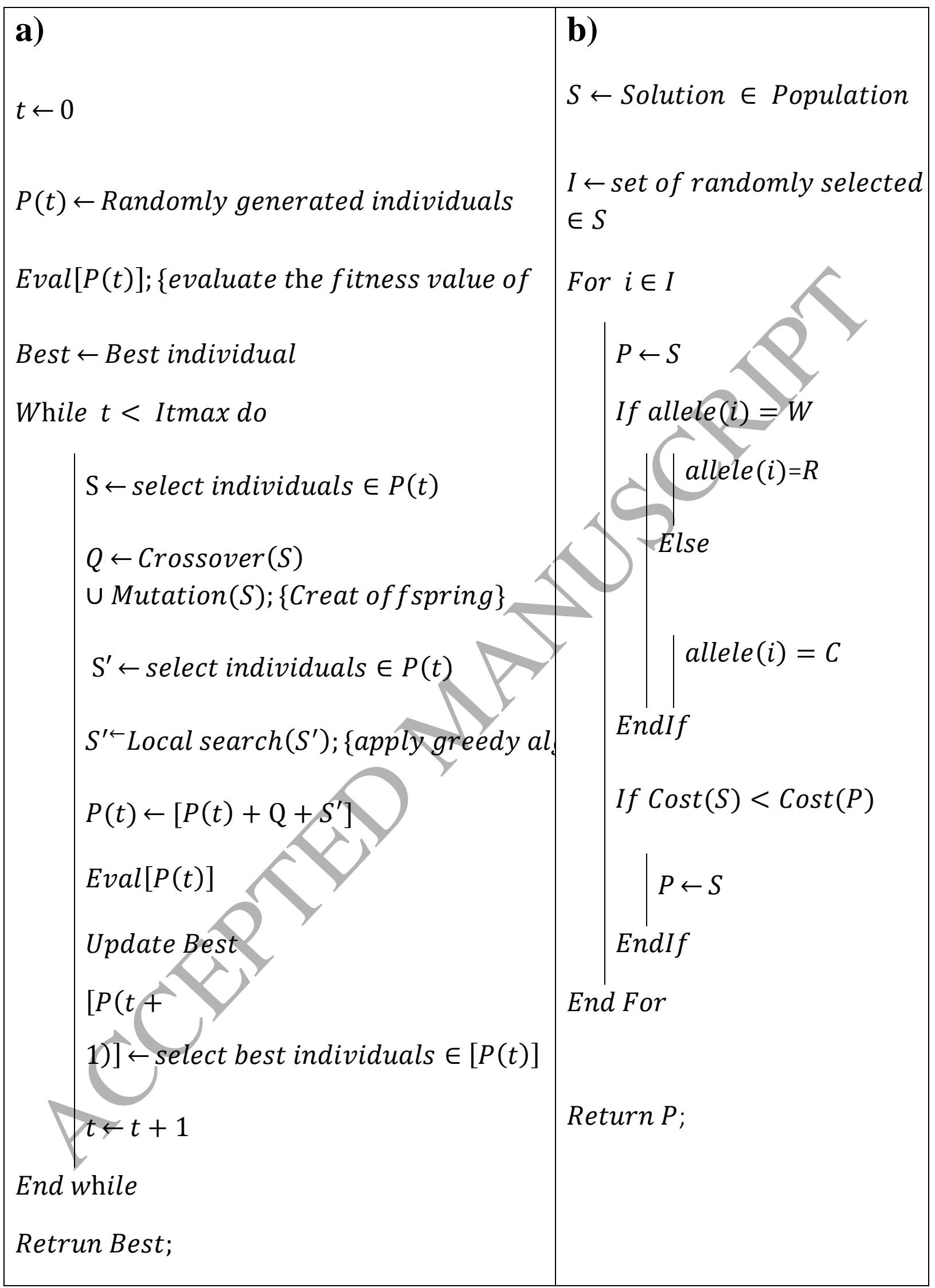




\subsection{Parameter Tuning}

The parameters of the metaheuristic algorithms affect the efficiency and effectiveness of the metaheuristic algorithms. therefore, to achieve the best performance, they need to be tuned prior to their implementation. One of the methods which is popularly used to adjust the parameters is the Taguchi method. Taguchi uses orthogonal arrays in order to investigate a large number of controllable factors with a small number of experiments [51]. Taguchi's method finds the optimal level of controllable factors by minimizing the effect of noise. In order to evaluate the variation of the response, the signal to noise ratio $(S / N)$ is calculated according to Eq. (39), in which $Y$ denotes the response value and $n$ shows the number of orthogonal arrays.

$S / N=-10 \times \log \left(S\left(Y^{2}\right) / n\right)$

The applied parameters with their relative ranges are shown in Table 1. According to the proposed parameter combinations for the developed Hybrid GA shown in Appendix 2, ten problems generated randomly with different sizes and specifications are solved five times in order to find the average objective values that are used as the response in Taguchi analysis. Fig. 2 shows the S/N ratios obtained for the developed Hybrid GA. According to these results, the best parameter combination for each algorithm is found by observing the highest dot for each parameter A (Npop), B (Pc), C (Pm), D (MaxIt), E (GSp), and F (GSi). For example, for parameters A the better value is found in the second level, and similarly for B second level, and for C, D, E and F third level are selected. The Taguchi design and corresponding results for the GA can be found in Appendix 3.

Table 1. Parameter levels

\begin{tabular}{|c|c|c|c|c|c|}
\hline Algorithm & $\begin{array}{l}\text { Algorithm } \\
\text { parameters }\end{array}$ & $\begin{array}{l}\text { Parameter } \\
\text { range }\end{array}$ & $\operatorname{Low}(1)$ & Medium(2) & $\operatorname{High}(3)$ \\
\hline \multirow{6}{*}{ Hybrid GA } & Npop (A) & 300 & 100 & 200 & 300 \\
\hline & & $0.6-0.9$ & 0.6 & 0.75 & 0.9 \\
\hline & & $0.3-0.5$ & 0.3 & 0.4 & 0.5 \\
\hline & & $100-300$ & 100 & 200 & 300 \\
\hline & GSp (E) & $0.2-0.6$ & 0.2 & 0.4 & 0.6 \\
\hline & GSi (F) & $0.1-0.3$ & 0.1 & 0.2 & 0.3 \\
\hline
\end{tabular}




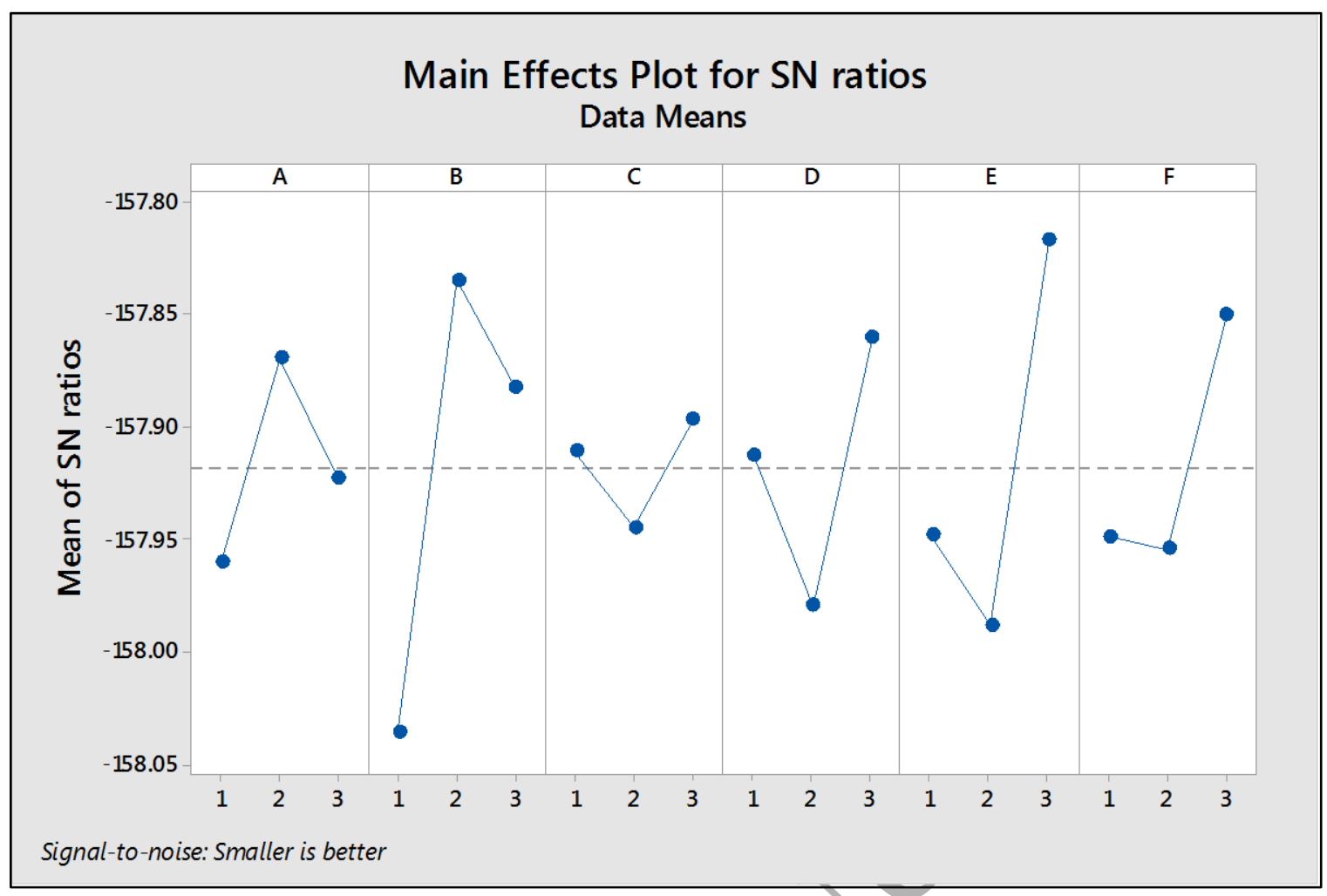

Fig. 2. Main effects plot for $S / N$ ratios: Hybrid GA

The Taguchi method is performed using Minitab, 18 and the parameter-tuned algorithms are coded in MATLAB (R2016b) and implemented on an Intel® Core $^{\mathrm{TM}}$ i5-3210M CPU @ $2.50 \mathrm{GHz}$ laptop with 6 GB RAM, 3 MB L3 Cache, and 256 kb L2 Cache.

\section{Case Study}

Online retailers are always coping with problems which stem from their logistics operations. The increase in fuel costs in recent years has made logistics companies increase the rates for the services they offer to retailers. To solve this problem, and to continue offering competitive prices in the market, Amazon announced its Amazon Prime Air project to be launched in the near future. The reason for this decision lies in the significantly lower costs of aerial delivery over ground delivery. As mentioned by [52], the cost of delivery for a 2 kilogram package over a course of 10 kilometers is approximately 0.1 USD by air and 5 USD via ground routes, which translates to 0.49 USD in savings for each kilometer traveled. On the other hand, Amazon has claimed that they intend to deliver the purchased packages in half an hour of the issued time for users of the Prime Air service. Thus, waiting time is used as a parameter in the mathematical model to provide further insight into the effects of waiting time in this problem. It is expected that minimizing the waiting times would directly affect the number of drones required to serve the demand.

Considering a daily worldwide shipping volume of 15.6 million packages for Amazon [53], and on the premise that $25 \%$ of these items are shipped in the U.S., [54] has reported that the daily average number of deliveries per person is 0.0122295 packages.

In this study, in order to realistically depict the daily demand in the U.S., the fraction of the domestic shipping packages are considered to be $10 \%, 20 \%, 30 \%$, and $40 \%$. Using these rates, and according to the fact that $86 \%$ of orders shipped by Amazon weigh less than 5 pounds and could be delivered by 
drones [55], the daily number of shipping items could be calculated as 0.004207, 0.008414, 0.012621, and 0.016828 packages per person, respectively. The city of San Francisco, with 850,000 inhabitants, is considered for the case study of this research. Depicted in Fig 3.a is the transportation network of the city with 40,326 nodes and 68,609 edges, provided using Esri maps and the ArcGIS software. As illustrated in Fig 3.b, 110 nodes are selected as the potential locations for launch and refuel stations.

Considering the population of San Francisco, the different levels of daily demand of the city would be 3,576, 7,152, 10,728, and 14,304 packages. According to U.S. regulations, drones should fly no faster than $100 \mathrm{mph}$ and no higher than 400 feet (Federal Aviation Administration, 2016). Taking these regulations into account, Amazon would initiate drone delivery operations for the items that weigh less than 5 pounds [57]. The endurance of each drone varies from 10 [58] to 15 miles [59]. The speed of each drone is assumed to be $50 \mathrm{mph}$ [55], $60 \mathrm{mph}$ [59], and $80 \mathrm{mph}$ [60]. Using these specifications, the price of each drone ranges from 3000 to 5000 USD [54]. Here, to account for different possibilities, the endurance of drones is assumed to be $10,13,15$, and 18 miles and the speed of each drone is supposed to be $50,60,70$, and $80 \mathrm{mph}$. Considering these specifications, four different price levels of drones could be 3000, 4000, 5000, and 6000 USD. Considering a planning period of 10 years, the premise that the drones have a service life of 5 years [61], and using an interest rate of $2 \%$ per year [62], the annual cost for purchasing each drone could be calculated according to Eq. 40:

$$
\text { Annual Cost }=\text { Purchasing cost } *(1+(P / F, 2 \%, 5)) *(A / P, 2 \%, 10)
$$

$\boldsymbol{A}, \boldsymbol{P}$, and $\boldsymbol{F}$ are the annual, present, and future value of the money, respectively [63]. Using Eq. 40 , four different levels for the annual purchasing cost of drones are calculated as 637, 849, 1061, and 1273 USD.

The average area of Amazon's delivery stations is roughly estimated as 84,389 square feet [64]. Since it is assumed that the delivery stations in the city would not be unique, the area of each station is considered equal to 42,000 square feet. Since the land price in San Francisco fluctuates from 400 to 1200 USD per square foot [65] and the ayerage construction cost of logistic centers is estimated equal to 88 USD per square foot [66], four different levels of the establishment cost for each delivery center is premised as 22.6, 33.1, 43.6, and 54.1 million dollars. Each refuel station is considered to have an area of 10,000 square feet, equipped with 200 extra batteries each costing 200 USD. The different levels of the establishment cost of refuel stations are supposed to be 5, 7.9, 10.4, and 12.9 million dollars. Considering a planning period of 10 years and a $2 \%$ interest rate, and assuming the salvage value of the land as $95 \%$ of its purchasing price, the annual cost of opening launch stations is calculated according to Eq. 41.

$$
\begin{gathered}
\text { Annual Cost }=(\text { land } \text { price }+ \text { construction cost }) *(A / P, 2 \%, 10)- \\
\text { land's salvage value } *(A / F, 2 \%, 10)
\end{gathered}
$$

On the premise that each battery could be used for a 2-year period, the annual cost of refuel stations is calculated according to Eq. 42.

$$
\begin{aligned}
\text { Annual Cost }= & (\text { land price }+ \text { construction cost }) *(A / P, 2 \%, 10)+ \\
& \text { battries cost } *\left(A /_{P}, 2 \%, 2\right)-\text { land's salvage value } * \\
& \left(A /_{F}, 2 \%, 10\right)
\end{aligned}
$$


Using Eq. 41, four different levels of the annual opening costs for each delivery station are calculated as $0.8757,1.1337,1.3916$, and 1.6496 million dollars. Based on Eq. 24, the four different levels of the annual costs for each refuel station are $0.2291,0.2905,0.3519$, and 0.4133 million dollars.
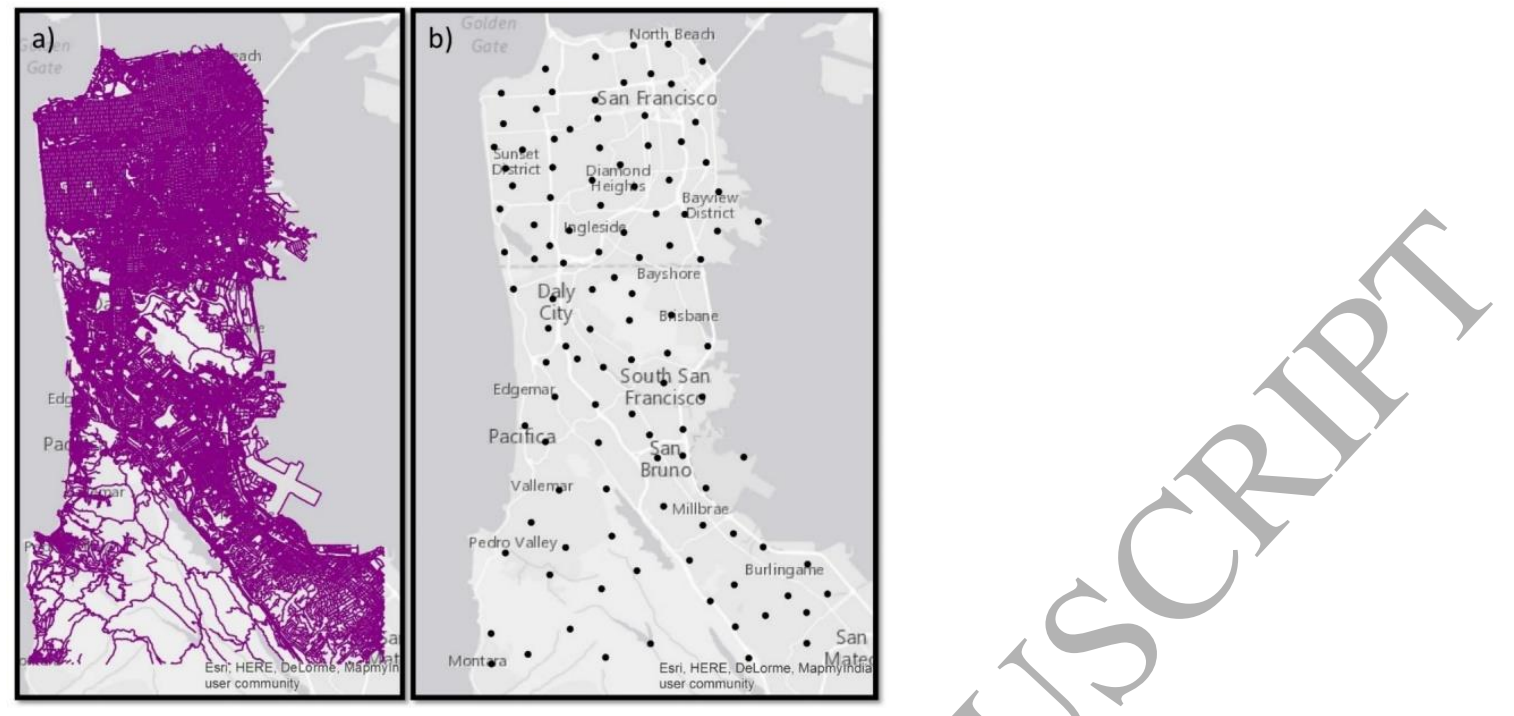

Fig. 3. Acquired from ArcGIS; a) San Francisco's transportation network. b) Candidate locations

\section{Results and Discussion}

As previously mentioned, the feasibility level " $\alpha$ " in a fuzzy mathematical formulation is decided by the decision maker and varies from 0.6 to 1 . Logically, the $\alpha$ level is changed if the obtained solution did not satisfy the decision maker until a satisfactory result is obtained. In strategic decisions, it is particularly important that the solution is processed from the minimum acceptable level to the maximum due to the cost that would be imposed on the system at a higher feasibility level. Hence, in the present study, $\alpha$ is set to 0.6 and the results are elaborated on that basis and with regards to the factual information (discussed in section 4). Table 2 represents the required infrastructure for a specific intended waiting time of delivery. Since the obtained solution is satisfying, proceeding to higher levels of $\alpha$ is not necessary.

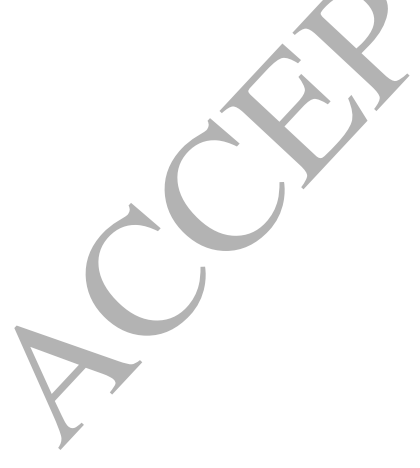


Table 2. The outcomes of the problem for different values of waiting time

\begin{tabular}{|c|c|c|c|c|c|c|}
\hline $\begin{array}{c}\text { Maximum } \\
\text { acceptable } \\
\text { Waiting } \\
\text { time (min) }\end{array}$ & $\begin{array}{c}\text { Total } \\
\text { Number of } \\
\text { the } \\
\text { warehouses }\end{array}$ & $\begin{array}{c}\text { Total Number of } \\
\text { the recharge } \\
\text { stations }\end{array}$ & $\begin{array}{c}\text { Total } \\
\text { Number of } \\
\text { the Drones }\end{array}$ & $\begin{array}{c}\text { Travel } \\
\text { Distance } \\
(\mathbf{k m})\end{array}$ & $\begin{array}{c}\text { Total Cost } \\
\text { (USD) }\end{array}$ & $\begin{array}{l}\text { CPU } \\
\text { Time } \\
\text { (sec) }\end{array}$ \\
\hline 30 & 2 & 38 & 1502 & 312,008 & $17,981,761$ & 2412 \\
\hline 60 & 2 & 32 & 1550 & 310,841 & $16,096,009$ & 24789 \\
\hline 90 & 6 & 10 & 361 & 175,690 & $13,720,939$ & 30127 \\
\hline 120 & 7 & 5 & 309 & 177,280 & $13,655,123$ & 9821 \\
\hline 150 & 6 & 5 & 321 & 1 & $12,028,811$ & 8914 \\
\hline 180 & 7 & 6 & 289 & 166,610 & $13,917,069$ & 8267 \\
\hline 210 & 6 & 10 & 356 & & $13,779,604$ & 20497 \\
\hline 240 & 6 & 5 & 352 & 03 & $12,134,699$ & 8539 \\
\hline 270 & 6 & 5 & & 150,820 & $11,944,968$ & 7156 \\
\hline 300 & 6 & 8 & & 160,331 & $12,960,599$ & 22296 \\
\hline 360 & 6 & 7 & & 189,698 & $12,799,565$ & 22439 \\
\hline 420 & 6 & 5 & & 155,605 & $11,965,846$ & 20794 \\
\hline
\end{tabular}

Table 2 provides the required infrastructure (the number of drones, the total number of warehouses and the total number of recharge stations), as well as the total distance traveled and cost in each setting. The significant cost saving in this approach is due to two important factors:

a. Using an aerial delivery system (0.49 USD saved per kilometer).

b. Considering both the launch and refuel stations in optimizing the problem translates into a cost saving up to 50 million dollars in a year.

The importance of the second factor becomes even more prominent by considering the fact that the application of a simple facility location problem in which launch stations are disregarded would make the problem infeasible for small values of maximum waiting time.

The effect of the waiting time on the outcome of the model is twofold: first, it is obvious that the shortest path between any demand point and its nearest warehouse should be less than the maximum allowed waiting time. Therefore, by decreasing the waiting time, the number of stations required to satisfy the demand increases. Conversely, waiting time is dependent on the number of servers and their service rate. Thus, by decreasing the waiting time, the number of servers needed (which are drones for this study) increases.

In order to apply the proposed model to another metropolis and under different settings, the case of Tehran with 92,471 nodes and 124,171 edges and a demand of 50000 packages per day is studied. As it is shown in Appendix 4, the aerial delivery system will result in a cost saving up to 9.2 million dollars in a year. Although the results are still encouraging, the savings are not as significant as those achieved under the conditions found in San Francisco. The main reason for launching the aerial 
delivery system is to decrease transportation cost which has experienced a great alternation due to the increase in fuel prices. In Tehran, the fuel price is considerably lower compared with other countries as the government imposes subsidy on fuel costs. Thus, the decrease in fuel consumption does not result in significant savings in transportation costs. Also, the demand rate in Tehran is not as large as that of San Francisco and the price of drones is comparatively higher in Tehran. The change in these parameters has made the savings achieved in Tehran lower compared with San Francisco and one should notice the parameters such as city logistics and local conditions can highly affect the results.

\section{Conclusion}

There have been many studies on the optimization of drone-based delivery systems through various criteria such as fuel consumption, endurance, hijacking, battery weight, and obstacle avoidance. Nevertheless, only a few of them are concerned with the operational aspects of the system. Similarly, to the best knowledge of the authors and the available literature, studies on the economics and logistics of the drone delivery systems based on the status of both launch and refuel stations, if any, are scarce. Invariably, decision making about the number of the launch and refuel stations is highly affected by the uncertainty of the parameters of the problem. Therefore, an adequate optimization solution should be deeply concerned about how to render their effects insignificant due to these uncertainties. Our study has attempted to fill these gaps by taking cognizance of all the major factors. Utilizing the fuzzy variables, the optimization model proposed could accommodate the factor of uncertainty in the solution procedure for determining the correct number of launch stations, refuel stations, and drones for an intended delivery time with minimum cost. The fuzzy possibilistic approach, as one of the most useful tools for defuzzification of the problem, is employed to determine the crisp equivalent of the proposed model. The resulting problem has a strong nonlinear nature, hence the GA is adapted to solve the problem. The proposed models in this study provide a proper tool for managers to establish an aerial delivery system with a proper setting that is essential in the current competitive market. The case studies performed on two cities indicate that parameters such as transportation cost per kilometer (which accounts for costs including fuel and drone maintenance and depreciation), demand rate and geographical distribution play an important role in determining the system outcomes and decision makers should provide consistent estimation of these parameters to achieve a reliable result.

This study accounts for waiting tímes of the customers and ensures that the purchased products are delivered to the customers within a time window specified by management. Future studies may involve vehicle routing for the case where the payload of the drones allows for more than one demand to be satisfied on each trip of the drone.

\section{References:}

[1] Magretta, "Why business models matter," Harv. Bus. Rev., vol. 80, no. 5, pp. 86-92, 133, 2002.

[2] V. A. Zeithaml, A. Parasuraman, and L. L. Berry, "Problems and Strategies in Services Marketing," J. Mark., vol. 49, no. 2, p. 33, 1985.

[3] C. C. Murray and A. G. Chu, "The flying sidekick traveling salesman problem: Optimization of drone-assisted parcel delivery," Transp. Res. Part C Emerg. Technol., vol. 54, pp. 86-109, 2015.

[4] H. Kwon, J. Kim, and Y. Park, "Applying LSA text mining technique in envisioning social impacts 
of emerging technologies: The case of drone technology," Technovation, vol. 60-61, pp. 1528, 2017.

[5] K. Dorling, J. Heinrichs, G. G. Messier, and S. Magierowski, "Vehicle Routing Problems for Drone Delivery," IEEE Trans. Syst. Man, Cybern. Syst., vol. 47, no. 1, pp. 70-85, 2017.

[6] M. Melo, S. Nickel, and F. Saldanha-Da-Gama, "Facility location and supply chain management-A review," Eur. J. Oper., vol. 196, no. 2, pp. 401-412, 2009.

[7] A. Klose and A. Drexl, "Facility location models for distribution system design," Eur. J. Oper. Res., vol. 162, no. 1, pp. 4-29, 2005.

[8] C. S. ReVelle, H. A. Eiselt, and M. S. Daskin, "A bibliography for some fundamental problem categories in discrete location science," Eur. J. Oper. Res., vol. 184, no. 3, pp. 817-848, 2008.

[9] M. Wen, Z. Qin, R. Kang, and Y. Yang, "The capacitated facility location-allocation problem under uncertain environment," J. Intell. Fuzzy Syst., vol. 29, no. 5, pp. 2217-2226, 2015.

[10] R. Sarraj, E. Ballot, S. Pan, D. Hakimi, and B. Montreuil, "Interconnected logistic networks and protocols: simulation-based efficiency assessment," Int. J. Prod. Res., vol. 52, no. 11, pp. 3185-3208, Jun. 2014.

[11] S. Park, L. Zhang, and S. Chakraborty, "Design space exploration of drone infrastructure for large-scale delivery services," in Proceedings of the 35th International Conference on Computer-Aided Design - ICCAD'16, 2016, pp. 1-7.

[12] S. Mourelo Ferrandez, T. Harbison, T. Weber, R. Sturges, R. Rich, and R. Rich, "(JAVIER ARAGON)Optimization of a truck-drone in tandem delivery network using k-means and genetic algorithm," J. Ind. Eng. Manag., vol. 9, no. 2, p. 374, 2016.

[13] G. Xiang, A. Hardy, M. Rajeh, and L. Venuthurupalli, "Design of the life-ring drone delivery system for rip current rescue," in 2016 IEEE Systems and Information Engineering Design Symposium, SIEDS 2016, 2016, pp. 181-186.

[14] M. Golabi, S. M. Shavarani, and G. Izbirak, "An edge-based stochastic facility location problem in UAV-supported humanitarian relief logistics: a case study of Tehran earthquake," Nat. Hazards, vol. 95, no. 9-12, pp. 3141-3153, 2017.

[15] M. Kim and E.T. Matson, "A Cost-Optimization Model in Multi-agent System Routing for Drone Delivery," Springer, Cham, 2017, pp. 40-51.

[16] J. E. Scott and C. H. Scott, "Drone Delivery Models for Healthcare," in Proceedings of the 50th Hawaii International Conference on System Sciences, 2017, pp. 3297-3304.

[17] Kong, M. Kuby, and A. Murray, "A Deviation Flow Refueling Location Model for Continuous Space: A Commercial Drone Delivery System for Urban Areas," in Advances in Geographic Information Science, D. Griffith, Y. Chun, and D. Dean, Eds. Springer, Cham, 2017, pp. 125132.

[18] B. Boffey, R. Galvão, and L. Espejo, "A review of congestion models in the location of facilities with immobile servers," Eur. J. Oper. Res., vol. 178, no. 3, pp. 643-662, 2007.

[19] O. Berman, R. C. Larson, and S. S. Chiu, "Optimal Server Location on a Network Operating as an M/G/1 Queue," Oper. Res., vol. 33, no. 4, pp. 746-771, Aug. 1985. 
[20] R. Batta and O. Berman, "A location model for a facility operating as anM/G/k queue," Networks, vol. 19, no. 6, pp. 717-728, Oct. 1989.

[21] O. Berman and R. R. Mandowsky, "Location-allocation on congested networks," Eur. J. Oper. Res., vol. 26, no. 2, pp. 238-250, Aug. 1986.

[22] S. A. Nozaki and S. M. Ross, "Approximations in Finite-Capacity Multi-Server Queues with Poisson Arrivals," J. Appl. Probab., vol. 15, no. 4, p. 826, Dec. 1978.

[23] R. Logendran and M. Terrell, "Uncapacitated plant location-allocation problems with price sensitive stochastic demands," Comput. Oper. Res., vol. 15, no. 2, pp. 189-198, 1988.

[24] E. H. Sabri and B. M. Beamon, "A multi-objective approach to simultaneous strategic and operational planning in supply chain design," Omega, vol. 28, no. 5, pp. 581-598, 2000.

[25] J. Zhou and B. Liu, "Modeling capacitated location-allocation problem with fuzzy demands," Comput. Ind. Eng., vol. 53, no. 3, pp. 454-468, 2007.

[26] L. A. Zadeh, G. J. Klir, and B. Yuan, Fuzzy sets, fuzzy logic, and fuzzy systems: selected papers by Lotfi A. Zadeh. Singapore: World Scientific Publishing Co., Inc., 1996.

[27] L. A. Zadeh, “Fuzzy sets," Inf. Control, vol. 8, no. 3, pp. 338-353, 1965.

[28] U. Bhattacharya, J. R. Rao, and R. N. Tiwari, "Bi-criteria multi facility location problem in fuzzy environment," Fuzzy Sets Syst., vol. 56, no. 2, pp. 145-153, 1993.

[29] J. Darzentas, "A discrete location model with fuzzy accessibility measures," Fuzzy Sets Syst., vol. 23, no. 1, pp. 149-154, 1987.

[30] S. Niroomand, S. Mosallaeipour, A. Mahmoodirad, and B. Vizvari, "A study of a robust multiobjective supplier-material selection problem," IMA J. Manag. Math. Oxford Univ. Press., pp. 1-25, Feb. 2018.

[31] B. Liu, Uncertainty theory: a branch of mathematics for modeling human uncertainty, 1st ed. Springer, 2010.

[32] D. B. Liu, "Uncertainty Theory," in Uncertainty Theory, Berlin: Springer Berlin Heidelberg, 2007, pp. 205-234.

[33] Y. Cui, Y.-P. Cui, and L. Yang, "Heuristic for the two-dimensional arbitrary stock-size cutting stock problem," Comput. Ind. Eng., vol. 78, pp. 195-204, 2014.

[34] J.N. K. Liu and E. Y. Zhang, "An investigation of factors affecting customer selection of online hotel booking channels," Int. J. Hosp. Manag., vol. 39, pp. 71-83, 2014.

[35] D. B. Liu, "Uncertainty Theory," in Uncertainty Theory, 5th ed., Department of Mathematical Sciences Tsinghua University Beijing 100084, China: Uncertainty Theory Laboratory, 2016, pp. 205-234.

[36] S. Mosallaeipour, A. Mahmoodirad, S. Niroomand, and B. Vizvari, "Simultaneous selection of material and supplier under uncertainty in carton box industries: a fuzzy possibilistic multicriteria approach," Soft Comput., vol. 22, no. 9, pp. 2891-2905, 2018.

[37] A. Ben-Tal and A. Nemirovski, "Robust Convex Optimization," Math. Oper. Res., vol. 23, no. 4, pp. 769-805, Nov. 1998. 
[38] A. Ben-Tal and A. Nemirovski, "Robust solutions of uncertain linear programs," Oper. Res. Lett., vol. 25, no. 1, pp. 1-13, Aug. 1999.

[39] L. El Ghaoui, F. Oustry, and H. Lebret, "Robust Solutions to Uncertain Semidefinite Programs," SIAM J. Optim., vol. 9, no. 1, pp. 33-52, Jan. 1998.

[40] D. Bertsimas and M. Sim, "The Price of Robustness," Oper. Res., vol. 52, no. 1, pp. 35-53, Feb. 2004.

[41] M. Jiménez, M. Arenas, A. Bilbao, and M. V. Rodri'guez, "Linear programming with fuzzy parameters: An interactive method resolution,” Eur. J. Oper. Res., vol. 177, no. 3, pp. 15991609, Mar. 2007.

[42] M. Jiménez, "Ranking Fuzzy Numbers Through the Coparison of its Expected Intervals," Int. J. Uncertainty, Fuzziness Knowledge-Based Syst., vol. 04, no. 04, pp. 379-388, Aug. 1996.

[43] M. Inuiguchi and J. Ramík, "Possibilistic linear programming: a brief review of fuzzy mathematical programming and a comparison with stochastic programming in portfolio selection problem," Fuzzy Sets Syst., vol. 111, no. 1, pp. 3-28, Apr. 2000.

[44] Y.-J. Lai and C.-L. Hwang, "A new approach to some possibilistic linear programming problems," Fuzzy Sets Syst., vol. 49, no. 2, pp. 121-133, Jul. 1992.

[45] M. Jamil, A. Baveja, and R. Batta, "The stochastic queue center problem," Comput. Oper. Res., vol. 26, no. 14, pp. 1423-1436, Dec. 1999.

[46] F. M. Moghadas, E. Monabbati, and H. T. Kakhki, "Emergency Location Problems with an M/G/k Queueing System," Iran. J. Oper. Res., vol. 4, no. 1, pp. 1-13, 2013.

[47] M. Arenas Parra, A. Bilbao Terol, B. Pérez Gladish, and M. V. Rodríguez Uría, "Solving a multiobjective possibilistic problem through compromise programming," Eur. J. Oper. Res., vol. 164, no. 3, pp. 748-759, Aug. 2005.

[48] J. H. Holland, Adaptation in natural and artificial systems: An introductory analysis with applications to biology, control, and artificial intelligence. Oxford, England: University of Michigan Press, 1975.

[49] M. Ghadiri Nejad, S. M. Shavarani, B. Vizvári, and R. V. Barenji, "Trade-off between process scheduling and production cost in cyclic flexible robotic cells," Int. J. Adv. Manuf. Technol., vol. 96, no. 1-4, pp. 1081-1091, 2018.

[50] P. Guo, W. Cheng, and Y. Wang, "Hybrid evolutionary algorithm with extreme machine learning fitness function evaluation for two-stage capacitated facility location problems," Expert Syst. Appl., vol. 71, pp. 57-68, Apr. 2017.

[51] S. M. Mousavi, S. T. A. Niaki, E. Mehdizadeh, and M. R. Tavarroth, "The capacitated multifacility location-allocation problem with probabilistic customer location and demand: two hybrid meta-heuristic algorithms," Int. J. Syst. Sci., vol. 44, no. 10, pp. 1897-1912, 2013.

[52] C. Smith, "The surprising facts about who shops online and on mobile," Business Insider, 2015. [Online]. Available: http://businessinsider.com/the-surprising-demographics-of-whoshops-online-and-on-mobile-2014-6. [Accessed: 21-Apr-2018].

[53] T. Cheredar, "At peak, Amazon sold a whopping 306 items per second in 2012," VentureBeat, 
2012. [Online]. Available: https://venturebeat.com/2012/12/27/at-peak-amazon-sold-awhopping-306-items-per-second-in-2012/. [Accessed: 21-Apr-2018].

[54] A. W. Sudbury and E. B. Hutchinson, "A Cost Analysis of Amazon Prime Air (Drone Delivery)," J. Econ. Educ., no. 1, pp. 1-12, 2016.

[55] E. Kim, "The most staggering part about Amazon's upcoming drone delivery service," Business Insider, 2016. [Online]. Available: http://www.businessinsider.com/cost-savings-fromamazon-drone-deliveries-2016-6. [Accessed: 22-Apr-2018].

[56] L. Dorr and A. Duquette, "Fact Sheet - Small Unmanned Aircraft Regulations (Part 107)," Federal Aviation Adminstration, 2016. [Online]. Available: https://www.faa.gov/news/fact_sheets/news_story.cfm?newsld=20516. [Accessed: 22-Apr2018].

[57] N. Lavars, "Amazon to begin testing new delivery drones in the US," New Atlas, 2015. [Online]. Available: https://newatlas.com/amazon-new-delivery-drones-us-faaapproval/36957/. [Accessed: 19-Apr-2018].

[58] R. Whitwam, "Amazon reveals how Prime Air drone delivery will work, still doesn't know how much it will cost," ExtremeTech, 2016. [Online]. Available:

https://www.extremetech.com/extreme/221517-amazon-reveals-how-prime-air-dronedelivery-will-work-still-doesnt-know-how-much-it-will-cost. [Accessed: 21-Apr-2018].

[59] L. Johnson, "9 things you need to know about the Amazon Prime Air drone delivery service," Digital Spy, 2017. [Online]. Available:

http://www.digitalspy.com/tech/feature/a820748/amazon-prime-air-drone-delivery-service/. [Accessed: 22-Apr-2018].

[60] E. Betters, "How does Amazon Prime Air work and where is drone delivery available?," Pocket-link, 2016. [Online]. Available: https://www. pocketlint.com/drones/news/amazon/139746-how-does-amazon-prime-air-work-and-where-isdrone-delivery-available. [Accessed: 19-Apr-2018].

[61] J. Swope, "The Economics Behind Amazon's Drone Delivery Service," 2013. [Online]. Available: http://www,johnswope.com/?p=83. [Accessed: 21-Apr-2018].

[62] Bankrate, “California CD Rates," 2018. [Online]. Available: https://www.bankrate.com/california/cd-rates.aspx. [Accessed: 19-Apr-2018].

[63] L. T. Blank and A. J. Tarquin, Engineering economy, 7th ed. New York: McGraw-Hill HigherEducation, 2011.

[64] MWPVL International Inc., "Amazon Distribution Network Strategy," 2018. [Online]. Available: http://www.mwpvl.com/html/amazon_com.html. [Accessed: 19-Apr-2018].

[65] Trulia, "San Francisco Home Prices and Heat Map," 2017. [Online]. Available: https://www.trulia.com/home_prices/California/San_Francisco-heat_map/. [Accessed: 21Apr-2018].

[66] COMPASS, "International Warehouse / Logistics Center Costs," COMPASS International Inc., 2017. [Online]. Available: https://www.compassinternational.net/international-warehouselogistics-center-costs/. [Accessed: 21-Apr-2018]. 